\title{
A abordagem das dores recorrentes na infância
}

\section{The approach of recurrent pain in children}

\author{
Ana Paula Scoleze Ferrer ${ }^{1}$, Ana Cecília Silveira Lins Sucupira ${ }^{2}$
}

Ferrer APS, Sucupira ACSL. A abordagem das dores recorrentes na infância. Rev Med (São Paulo). 2010 abr.-jun.;89(2):65-9.

\begin{abstract}
RESUMO: A queixa de dores recorrentes é muito frequente na infância, sendo mais prevalentes a dor abdominal, a cefaleia e a dor em membros. O atendimento desses pacientes não é uma tarefa fácil, tanto pelo caráter vago e subjetivo do sintoma como pela complexidade de fatores que podem estar implicados em sua etiologia. O objetivo do presente artigo é apresentar uma proposta de abordagem dessas queixas de dores recorrentes em crianças.
\end{abstract}

DESCRITORES: Dor; Dor abdominal; Cefaleia; Anamnese; Saúde da criança; Recidiva.

$\mathrm{O}^{\mathrm{cos}}$ conceito de dor abdominal recorrente na infância foi introduzido em 1958 por Apley e Naish", que a definiram como "ocorrência de pelo menos três episódios de dor, durante um período de pelo menos três meses, com intensidade suficiente para interferir nas atividades habituais da criança". Atualmente, esse critério também é utilizado para outras queixas de dores na infância, como dor em membros e cefaleia².

Apesar de no Brasil não existirem estudos populacionais que permitam determinar a prevalência das dores recorrentes, sabe-se que é uma queixa muito freqüente nos consultórios pediátricos ${ }^{2}$. Estudos feitos na Dinamarca, por Oster e Nielsen ${ }^{3}$, encontraram uma prevalência de $20,6 \%$ de cefaléia, de $15,4 \%$ de dor em membros e de $14,4 \%$ para dor abdominal recorrentes na faixa etária de 6 a 19 anos. Além disso, não é raro que essas crianças se apresentem com mais de um tipo de dor, concomitantemente ou em fases diferentes, com uma localização de dor sucedendo a outra. No nosso meio, a tradição de associar parasitose com dor abdominal faz pensar que essa localização da dor seja a mais freqüente. Entretanto, muitas dessas queixas de dor não preenchem os critérios de Apley e Naish 1 .

Embora a queixa de dor recorrente seja muito comum, o atendimento desses pacientes não é uma tarefa fácil, tanto pelo caráter vago e subjetivo

\footnotetext{
1. Mestre em Pediatria pela Faculdade de Medicina da Universidade de São Paulo (FMUSP). Médica assistente do Ambulatório Geral de Pediatria Instituto da Criança - Departamento de Pediatria da Faculdade de Medicina da Universidade de São Paulo (FMUSP).

2. Doutora em Pediatria pela Faculdade de Medicina da Universidade de São Paulo (FMUSP). Mestre em Medicina Preventiva pela FMUSP. Médica assistente do Ambulatório Geral de Pediatria, Instituto da Criança - Departamento de Pediatria da Faculdade de Medicina da Universidade de São Paulo (FMUSP).

Endereço para correspondência: Ana Paula Scoleze Ferrer. Rua Dr. Enéas de Carvalho Aguiar, 647. São Paulo - SP. CEP: 05403 - 000. E-mail: ana.ferrer@icr.usp.br
} 
do sintoma como pela complexidade de fatores que podem estar implicados em sua etiologia. Imagine a seguinte situação: uma mãe traz seu filho de 7 anos à consulta referindo que o menino queixa de dor abdominal há 2 anos, semanalmente, e que já o levou a muitos médicos, os quais realizaram vários exames de fezes, todos negativos. Ela está muito preocupada, pois ninguém descobre a causa da dor, e, apesar de dizerem que não se trata de nada sério, o menino continua a ter dor. Frente a uma situação como a descrita, observa-se, na prática, duas condutas. Em uma, o pediatra assume uma atitude simplista e afirma para a família que "não é nada", não respondendo à demanda da família e não aliviando o seu sofrimento. Em outra, ele inicia um processo de investigação extenso e custoso à procura de sua etiologia. Essa busca por uma causa através da realização de inúmeros exames é, na maioria das vezes, injustificada, dada a baixa chance de o sintoma de dor recorrente estar associado a uma causa orgânica. No estudo de Oster e Nielsen ${ }^{3}$, a ocorrência de etiologia orgânica foi identificada em 5 a $10 \%$ das cefaléias, 5 a $13 \%$ das dores abdominais e apenas 3 a $4 \%$ das dores em membros recorrentes. A questão levantada frente a essas evidências é como, então, o pediatra poderia lidar com essa situação.

O princípio fundamental é a aceitação de que o modelo biomédico - aquele em que a explicação da doença restringe-se ao mundo biológico ou orgânico é inadequado e insuficiente para enfrentar o processo diagnóstico e terapêutico. Nas queixas de dores recorrentes, é essencial uma abordagem pautada em outro paradigma - o método clínico centrado no paciente / família ${ }^{4,5,6}$. e modelo de atendimento busca um conhecimento mais amplo da queixa trazida pelo paciente, preocupando-se não apenas a caracterização completa do sintoma e da doença, mas também com o entendimento de possíveis fatores psicossociais determinantes ou agravantes do quadro. Isso implica o conhecimento do sujeito e da família e de como a doença é vivenciada por eles. Essa anamnese ampliada permite, portanto, que o médico conheça "a dor", "a criança/adolescente" e "a família", obtendo informações essenciais para o diagnóstico e para o tratamento ${ }^{2}$. Deve ficar claro, entretanto, que o tratamento não significa terapêutica medicamentosa, mas sim responder à demanda do paciente e de sua família, isto é, esclarecer o motivo do sintoma e aliviar o sofrimento. Para tanto, um passo fundamental da anamnese é a exploração da hipótese para a causa da dor e/ou quais são os medos de uma doença específica que a família e o paciente tem². O Quadro 1 traz as principais perguntas que devem ser exploradas na anamnese da criança com queixa de dor recorrente ${ }^{2}$.

QUADRO 1: Dados a serem pesquisados na abordagem das dores recorrentes na infância

\section{Para caracterizar a dor}

- Há quanto tempo tem a dor?

- Como foi a primeira vez que teve a dor?

- Como é a dor?

- Com que freqüência ocorre?

- Onde é a dor? Tem alguma irradiação?

- Quando ocorrem os episódios?

- Onde ocorrem os episódios?

- Quais os principais fatores desencadeantes?

- O que faz a dor melhorar ou piorar?

- O quanto a dor atrapalha a vida da criança?

- Existem outros sintomas associados como febre, mal estar e perda de peso?

- Que tratamentos costuma fazer quando tem a dor?

- Tem outras queixas de dores recorrentes?

\section{Para conhecer a criança/adolescente}

- Qual a rotina de vida? O que a criança/adolescente faz no seu dia a dia?

- Quais as atividades preferidas?

- Como a família descreve o "temperamento" da criança/ adolescente?

- Houve mudança de comportamento recente?

- Como é o relacionamento com os pais e irmãos?

- Como é o relacionamento com os colegas e professores?

\section{Para conhecer a família}

- Na família, alguém tem queixa de dor ou doença crônica?

- Como costuma ser a reação dos pais à dor da criança?

- É comum levar a criança ao pronto-socorro por causa da dor?

- A família costuma dar medicação para a dor?

- Como a família caracteriza o relacionamento paiscriança?

- Houve algum evento crítico na família recentemente?

- Como a família reage aos momentos de conflito? 
Após a anamnese, deve-se realizar o exame físico completo no sentido de investigar a presença de sinais que indiquem comprometimento local ou sistêmico que podem apontar para uma possível causa orgânica para a dor.

Em crianças/adolescentes com dor abdominal recorrente recomenda-se como exames laboratoriais para a investigação inicial o hemograma completo, alguma prova de fase aguda (velocidade de hemossedimentação ou proteína $\mathrm{C}$ reativa), análise de urina com sedimento quantitativo (urina tipo I) e o exame protoparasitológico de fezes ${ }^{7}$. Para os pacientes com cefaleia ou dor em membros recorrente, não são indicados exames de rotina ${ }^{8,9}$. A necessidade de solicitar exames nesses casos ou de prosseguir a investigação da dor abdominal com outros exames, além dos já citados, será indicada pela existência de dados, detectados na anamnese ampliada e/ou no exame físico, conhecidos como "sinais de alerta"2,7,8,9. A presença do sinal de alerta não indica apenas a necessidade de aprofundar a investigação, mas também orienta o exame a ser solicitado. Assim, por exemplo, para uma criança com sintomas típicos de litíase urinária uma ultrassonografia de vias urinárias será mais útil. Os sinais de alerta são específicos para cada tipo de dor recorrente e são apresentados nos Quadros 2, 3 e 42,7,8,9.

QUADRO 2: Sinais de alerta na cefaléia recorrente

1. Presença de alteração neurológica.

2. Presença de alterações oculares como edema de papila, anisocoria, nistagmo, aparecimento de estrabismo, dificuldades visuais como diplopia e diminuição da acuidade visual.

3. Vômitos recorrentes com aumento na freqüência ou de início recente.

4. Mudança no padrão da cefaléia com aumento na intensidade e na freqüência.

5. Cefaléia recorrente matinal ou que desperta a criança.

6. Crianças com desaceleração da velocidade de crescimento.

7. Sintomas sugestivos de Diabetes insipidus.

8. Crianças com idade $\leq 3$ anos.

9. Pacientes com neurofibromatose.

Fonte: Sucupira, ACSL et al. Cefaléia recorrente In: Pediatria em consultório (2010) ${ }^{8}$

QUADRO 3: Sinais de alerta na dor abdominal recorrente

1. Dor de localização abdominal periférica (distante do umbigo), constante no local.

2. Dor que desperta a criança/adolescente do sono repetidas vezes.

3. Outras evidências de doença orgânica à anamnese e/ou ao exame físico como perda de peso, parada ou desaceleração de crescimento, febre recorrente de origem indeterminada, vômitos significantes ou biliosos, visceromegalias, massas abdominais, anormalidades perianais, diarréia crônica, artrite, sangramento gastrintestinal, entre outros.

4. História familiar de doença orgânica relevante - por exemplo, anemia falciforme, úlcera péptica, doença inflamatória intestinal, doença celíaca.

5. Alteração nos exames laboratoriais: Velocidade de hemossedimentação (VHS) ou proteína C reativa (PCR) elevada, alterações ao hemograma como anemia, leucocitose, morfologia celular alterada, alterações à análise de urina.

Fonte: modificado de Zuccolotto, SMC. Dor abdominal recorrente In: Pediatria em consultório (2010)

QUADRO 4: Sinais de alerta na dor em membros recorrente

1. Presença de dor localizada em pontos fixos, mas que não façam parte dos critérios de fibromialgia.

2. Dor com caracterísitcas "diferentes" (parestesias, formigamento, adormecimento etc).

3. Dor à palpação muscular.

4. Dor à movimentação passiva.

5. Diminuição da força muscular.

6. Dificuldade ou alteração à marcha.

7. Manifestações sistêmicas associadas ao quadro de dor.

8. Evolução com dor persistente e/ou que não responde a analgésicos.

Fonte: Zuccolotto, SMC et al. Dores recorrentes em membros In: Pediatria em consultório (2010) ${ }^{9}$ 
Imagine agora novamente a situação já descrita: uma mãe traz seu filho de 7 anos à consulta referindo que o menino queixa de dor abdominal há 2 anos, semanalmente, e que já o levou a muitos médicos, os quais realizaram vários exames de fezes, todos negativos. Ela está muito preocupada, pois ninguém descobre a causa da dor, e, apesar de dizerem que não se trata de nada sério, o menino continua a ter dor. Após o que foi exposto, o médico tem três alternativas:

1. Como não consegue relacionar a queixa apresentada a nenhuma doença orgânica, diz que não é nada e que com o tempo melhora. Nesse caso, a mãe sairá mais uma vez insatisfeita e o menino, com sua dor;

2. Procura detectar alguma doença orgânica e solicita, por exemplo, uma ultrassonografia de abdome. Como o exame provavelmente virá normal, a ansiedade de ambos, mãe e médico, aumentará, dando início a uma série de exames inconclusivos;

3. Utiliza o modelo proposto, aplicando a anamnese ampliada e realizando o exame físico completo. É fundamental que seja explorada a hipótese diagnóstica que a família tem, para que o médico possa esclarecer as preocupações apresentadas. Não detectando nenhum sinal de alerta na primeira consulta, deverá solicitar o hemograma completo, uma prova de fase aguda, a análise do sedimento de urina e pedir para a mãe trazer o resultado dos protoparasitológicos já realizados. Aqui, vale ressaltar que já nessa primeira consulta é importante que se explique para a família que esses exames permitem a exclusão de diversas patologias e que há grande probabilidade de resultarem normais, uma vez que cerca de $90 \%$ das dores recorrentes não têm etiologia orgânica definida. É fundamental deixar claro que, apesar de dificilmente se encontrar uma doença orgânica, a dor da criança é real e que fatores emocionais possivelmente estão provocando ou agravando o sintoma. O ideal é que seja marcado um retorno breve, tanto para checar os resultados dos exames, como para fortalecer o vínculo da relação médico-paciente para desvendar as circunstâncias envolvidas na gênese da dor. O retorno precoce também permite a obtenção de dados mais fidedignos em relação à dor, pois a lembrança dados importantes da dor (freqüência da dor, fatores desencadeantes, sintomas associados) é mais fiel em um período curto, além de deixar a família mais segura de que apesar de o médico não estar solicitando inúmeros exames, ele acredita na dor e está disposto a resolver o problema. Por fim, não é infreqüente que a própria consulta, ou melhor, a relação médico-paciente estabelecida, tenha efeito terapêutico ${ }^{10,11}$, isto é, a tranquilização da família e da própria criança/adolescente obtida nessa abordagem leva à melhora ou ao desaparecimento do sintoma.

Ferrer APS, Sucupira ACSL. The approach of recurrent pain in children. Rev Med (São Paulo). 2010 abr.-jun.;89(2):65-9.

\begin{abstract}
Recurrent pain is very common in childhood, the most frequent are abdominal pain, headache and limb pain. The care of these patients is not an easy task, because of both the subjective and the vagueness of the symptom as well as the complexity of factors that may be implicated in its etiology. The aim of this paper is to present a proposal to address the children with recurrent pain.
\end{abstract}

KEY WORDS: Pain; Abdominal pain; Headache; Medical history taking; Child health; Recurrence.

\section{REFERÊNCIAS}

1. Apley J, Naish N. Recurrent abdominal pains a field survey of 1000 alchool children. Arch Dis Child. 1958;33:165.

2. Sucupira ACSL, Bresolin AMB, Zuccolotto SMC. Dores recorrentes. In: Sucupira ACSL, Kobinger MEBA, Saito MI, Bourroul MLM, Zuccolotto SMC. Pediatria em consultório. São Paulo: Sarvier; 2010. p.696-8.

3. Oster J. Recurrent pain, headache and limb pains in children and adolescents. Pediatrics. 1972;50:429.
4. Brito de Sá A. O método clínico: o diagnóstico em situações diferenciadas: método clínico centrado no paciente; a medicina geral e familiar baseada na evidência. Lisboa; 2002. 26p. Disponível em: http://www. aefml.pt/med0006/aula_de_brito_sa.pdf.

5. American Academy of Pediatrics Committee on Hospital Care - Institute for Family-Centered Care, Policy Statement. Family centered care and the pediatrician's role. Pediatrics. 2003;112:691.

6. Evans RG. Patient centered medicine: reason, emotion, and human spirit? Some philosophical reflections 
on being with patients. Med Humanities. 2003;29:8.

7. Zuccolotto SMC. Dor abdominal recorrente. In: Sucupira ACSL, Kobinger MEBA, Saito MI, Bourroul MLM, Zuccolotto SMC. Pediatria em consultório. São Paulo: Sarvier; 2010. p.709-20.

8. Resegue R, Zuccolotto SMC. Cefaleia recorrente. In: Sucupira ACSL, Kobinger MEBA, Saito MI, Bourroul MLM, Zuccolotto SMC. Pediatria em consultório. São Paulo: Sarvier; 2010. p.699-708.

9. Zuccolotto SMC, Sucupira ACSL, Silva CAA. Dores recorrentes em membros. In: Sucupira ACSL, Kobinger
MEBA, Saito MI, Bourroul MLM, Zuccolotto SMC. Pediatria em consultório. São Paulo: Sarvier; 2010. p.721-35.

10. Balint $M$. The doctor, his patient and the ilness. London: Pitman; 1964.

11. Stewart MA. Effective physician-patient communication and health outcomes: a review. Can Med Assoc J. 1995;152:1423.

Artigo recebido em: 14/06/2010.

Artigo aceito em: 14/06/2010. 